\title{
Estado, políticas e gestão da educação: resistência ativa para uma agenda democrática com justiça social $^{1}$
}

\author{
State, policies and educational management: \\ active resistance for a democratic agenda with social justice \\ Estado, políticas y gestión educativa: \\ resistencia activa para una agenda democrática con justicia social
}

ALMERINDO JANELA AFONSO

Orcid ld: http://orcid.org/0000-0001-9879-5814

Universidade do Minho

\begin{abstract}
Resumo: Depois de uma breve revisitação sobre o conceito de Estado, a relação com a escola pública e as mudanças no conceito de cidadania, o autor faz uma incursão tangencial sobre a administração pública, para em seguida contextualizar a administração educacional enquanto campo específico de pesquisa e reflexão teórico-conceptual e política. $\mathrm{Na}$ parte final, são pontuadas algumas problemáticas que, do ponto de vista do autor, merecem uma atenção maior por parte dos pesquisadores em administração educacional e sociologia das organizações educativas. $\mathrm{O}$ artigo conclui retomando o apelo para que, também na educação, possa ser fortalecida uma resistência ativa para uma agenda democrática com justiça social.
\end{abstract}

Palavras-chave: Estado. Escola pública. Administração pública. Administração educacional.

\begin{abstract}
After a brief revisiting to the concept of State, the relationship with public schools and changes in the concept of citizenship, the author makes a related exploration of the concept of public administration, to then contextualize educational administration as a specific field of research, and theoretical-conceptual and political reflection. In the end, some questions are indicated that, from the author's point of view, deserve greater attention by researchers in educational administration and sociology of educational organizations. The article concludes by returning to an appeal so that an active resistance for a democratic agenda with social justice can also be strengthened in education.
\end{abstract}

Keywords: State, state school, public administration, educational administration

1 Este artigo insere-se no projeto Políticas, Governação e Administração da Educação - Educação 3 D - Democracia, Desigualdade e Diferença, financiado pelo Centro de Investigação em Educação, Instituto de Educação (CIEd) da Universidade do Minho (projetos UIDB/01661/2020 e UIDP/01661/2020), através de fundos nacionais da FCT/MCTES-PT. 
Resumen: Después de una breve revisión del concepto de Estado, la relación con la escuela pública y los cambios en el concepto de ciudadania, el autor realiza una incursión tangencial en el concepto de administración pública, para luego contextualizar la administración educativa como un campo específico de investigación y reflexión teórico-conceptual y política. En la parte final, se señalan algunos problemas que, desde el punto de vista del autor, merecen una mayor atención por parte de los investigadores en administración educativa y sociología de las organizaciones educativas. El artículo concluye reanudando el llamado, de modo que, también en educación, se pueda fortalecer una resistencia activa para una agenda democrática con justicia social.

Palabras clave: Estado, escuela pública, administración pública, administración educativa.

\section{INTRODUÇÃO}

Começando por fazer uma breve revisitação sobre o conceito de Estado, a relação com a escola pública e as mudanças no conceito de cidadania, o texto também convoca de forma sucinta uma ou outra perspetiva sobre a administração pública, de modo a situar as especificidades da administração educacional, enquanto campo de pesquisa e reflexão teórico-conceptual e política - e, sobretudo, para informar da existência de trabalhos de referência neste último campo, para o qual têm também contribuído colegas portugueses. Na parte final, mais ensaística, referenciam-se algumas problemáticas que merecem, do ponto de vista do autor, uma atenção maior por parte dos pesquisadores em administração educacional e em sociologia das organizações educativas. $\mathrm{O}$ artigo conclui retomando o apelo para que, também na educação, possa ser fortalecida uma resistência ativa para uma agenda democrática com justiça social².

\section{ESTADO E ESCOLA PÚBLICA}

Ainda que frequentemente repetida, a concepção que aqui convoco continua a ter algumas vantagens hermenêuticas porque o Estado, apesar das muitas transformações pelas quais tem passado, não deixou de ser um conjunto de aparelhos que, entre muitas outras funções, atualiza aquilo que Max Weber (2015, p. 62-63), há mais de um século, designou como sendo o "monopólio da violência física legítima" ou "considerada como legítima", ainda que esta definição

2 Este artigo decorre, genericamente, da conferência de abertura que proferi, com o mesmo título do XXIX Simpósio Brasileiro de Política e Administração da Educação, promovido pela ANPAE - "Estado, Políticas e Gestão da Educação: resistência ativa para uma agenda democrática com justiça social" (Curitiba, UFPR, 16 a 18 de abril de 2019). Quero registar um agradecimento especial à organização do evento, cujo convite me permitiu participar nesses dias de excelente ambiente acadêmico e profissional, apesar das angústias e incertezas decorrentes do espírito do tempo. 
não esgote toda a compreensão do Estado enquanto parte da "sociologia da dominação" que Weber procurou desenvolver (BIANCHI, 2014). Por sua vez, Pierre Bourdieu (2014) haveria de incluir a "violência simbólica" nessa concepção de Estado, escrevendo, a este propósito: “fiz um acréscimo à definição famosa de Max Weber [...] e que eu corrijo, acrescentando: 'monopólio da violência física e simbólica." (p. 30).

Em qualquer dos casos, o uso da violência física e simbólica transcendeu há muito o âmbito dos aparelhos do Estado, e as próprias fronteiras nacionais. Nos tempos que correm, as formas de violência simbólica (enquanto imposições dissimuladas) são atualizadas em diversos contextos sociais e organizacionais (das redes sociais aos media tradicionais), e a própria violência física (frequentemente ilegítima) está também mais presente, não apenas em regimes políticos autoritários, como na ação de órgãos repressivos e coercivos das sociedades supostamente democráticas, mas não raras vezes permeáveis ao exercício de imposições forçadas ou explícitas (quer no espaço público, quer no espaço privado).

No que diz respeito à problemática que justifica este texto e à sua inscrição genérica numa sociologia das políticas educacionais, relembro como adquirido que, ao longo da modernidade ocidental (e sobretudo a partir da consolidação do modelo escolar nas últimas décadas do seculo XIX), a escola pública, tutelada e financiada pelo Estado, foi (e em grande medida continua a ser) um dos lugares institucionais do exercício da violência simbólica, à qual se associou a violência física, apoiada por certas pedagogias e concepções de infância, particularmente dominantes em determinados períodos históricos e regimes políticos.

Não foi, portanto, sem razão que a imposição dissimulada de um currículo escolar, enquanto arbitrário cultural, foi denunciada por P. Bourdieu e J-C. Passeron (1970) e discutida por muitos outros autores, tendo em conta as (duradouras) desigualdades sociais transmutáveis em desigualdades escolares pela violência simbólica da ação pedagógica, e pela crença na suposta neutralidade da igualdade formal de oportunidades, as quais continuam a legitimar os processos e veredictos escolares pelo uso de instrumentos de avaliação e seleção (agora) metodologicamente aferidos e tecnicamente mais sofisticados.

Como facto amplamente conhecido, nos últimos dois séculos, a escola pública foi justificada (também) pelo contributo para a construção dos Estadosnação e respetivas cidadanias nacionais. Sem abandonar a visão durkheimiana que a concebia essencialmente como instância socializadora e de transmissão, entre gerações, do patrimônio cultural historicamente acumulado, a escola pública foi assumindo outras missões, entre as quais a de ajudar a criar ou reforçar uma identidade nacional resultante da fusão e assimilação (frequentemente coercitivas) 
de múltiplas culturas e identidades, em direção a um ideário comum (ou a uma "comunidade imaginada" conforme a conhecida designação de Benedict Anderson).

Nesse sentido, no que diz respeito ao Estado e à escola pública, a violência física e a violência simbólica reforçaram-se mutuamente. Ao contrário da atual conotação democrática (e ressalvando muitas exceções ainda existentes), a cidadania, enquanto decisão arbitrária do Estado, caracterizou-se, nos seus primórdios, mais pela exclusão (de muitos) do que pela inclusão (de alguns). Dito de outro modo, em muitos outros momentos históricos, a cidadania não democrática, ou restrita às lógicas do Estado-nação,

[...] não prescindiu da educação escolar na medida em que esta se assumiu como lugar privilegiado de transmissão (e legitimação) de um projeto societal integrador e homogeneizador, isto é, um projeto que pretendeu sobrepor-se (e substituir-se) às múltiplas subjetividades e identidades culturais, raciais, linguísticas e religiosas originárias. (AFONSO; LUCIO-VILLEGAS, 2007, p. 80-81).

Mas a escola pública (universal, obrigatória, laica e democrática), numa sociedade cada vez mais heterogênea e multicultural, confronta-se hoje com outras concepções e reivindicações de cidadania(s), algumas em forte tensão e contradição com o retorno à ideia de supremacia da cidadania e identidade nacionais, neste último caso, a ressurgir, sobretudo, nas agendas de movimentos xenófobos e de extrema direita em diferentes países. Também por isso, “A educação, tanto em sua forma simbólica quanto institucional, tem um papel essencial a desempenhar na luta contra o ressurgimento das culturas fascistas, narrativas históricas míticas e ideologias emergentes da supremacia e nacionalismos brancos." (GIROUX, 2019, p. 68).

Desde que foi confrontada com o aprofundamento da democratização política e cultural, a concepção (arbitrária) de uma cidadania monocultural, restrita às lógicas do Estado-nação, tem vindo a assumir outras concepções e justificações mais avançadas e progressistas (ou, pelo menos, não realizáveis anteriormente) que, de forma mais intensa, mas não sem tensões e contradições, se inscrevem nos movimentos e lutas por uma ampliação cada vez mais plural. As tecnologias da informação e da comunicação (TIC) tornaram-se instrumentos fundamentais não apenas para manter laços de nacionalismo (à distância) - "um nacionalismo de correio eletrônico e internet", como o entende Benedict Anderson (2016, p. 89) -, mas também para induzir novas concepções de cidadania e novas formas de preservação ou de confronto com identidades sedimentadas e emergentes (TSAVKKO-GARCÍA; DÍAZ, 2019). São cidadanias já não vinculadas necessariamente ao espaço nacional ("desnacionalizadas", como lhe chama Saskia 
Sassen, 2016), mas realizáveis em outros contextos, do local ao transnacional e ao global, constituindo, em muitos casos, "cidadanias em transição" (AFONSO; LUCIO-VILLEGAS, 2007) ou diaspóricas, capazes de reclamar, noutros espaços e lugares (como o ciberespaço) direitos humanos básicos e a possibilidade de expressão plural de projetos e identidades - já designadas também por "comunidades transnacionais imaginadas-virtuais" (LINS RIBEIRO, 2018, p. 17). Mas tudo isso é muito difícil de concretizar, sobretudo em situações como a de milhares de refugiados cuja legitimidade para ter voz e reclamar direitos de cidadania continuará, ainda por muito tempo e em muitos países, a ser posta em causa (explícita ou implicitamente) por questões econômicas e políticoideológicas, bem como pelos obstáculos que resultam da (ainda hegemônica) cultura ocidentalocêntrica, ou da escassa interiorização de concepções mais avançadas de justiça.

E, apanhado (como todos/as) por um acontecimento inesperado, é também impossível deixar de ter em conta as mudanças e instabilidades que, entretanto, se sucederam (e que estamos a experienciar atualmente) nos nossos estilos de vida, nas nossas convicções, nas nossas visões do mundo, da política, da religião, da economia, da família, da escola, etc., com a pandemia de Covid-19. Nesse contexto completamente inédito, há percursos que estão a ser refeitos por estranhas, paradoxais e inesperadas razões. Se é verdade que, em muitos casos, conforme abordei anteriormente, saímos da territorialização nacional das cidadanias para cidadanias em transição ou nômades (desterritorializadas), não há dúvida de que o confinamento obrigatório implica o retorno a outras formas de reterritorialização, reforçando a centralidade das TIC e revelando novos e inéditos impactos, nomeadamente na (re)construção das subjetividades. A propósito desse novo contexto, José Gil (2020, p. 11) escreve que "as subjectividades digitais poderão florescer e dominar. Serão subjetividades desterritorializadas, de certo modo, nómadas e transparentes, mas reterritorializadas no digital."3

Esta breve citação exemplifica bem como o Covid-19 se tornou rapidamente objeto de reflexão filosófica e, mais genericamente, uma problemática na área das Ciências Sociais e Humanas, para além da intensificação da produção do conhecimento científico no campo das ciências da vida e da saúde (do qual, neste caso, esperamos ansiosamente soluções duradouras de sobrevivência). Já vai sendo consensual admitir que esta pandemia está a mexer com todas as dimensões da vida em sociedade, e assim continuará durante muito tempo, não 
deixando também de suscitar interrogações ou pôr em causa, certamente de modos peculiares, as diferentes visões (e versões) político-ideológicas. Como escreve Miguel Salas (2020, p. 5):

A mobilização diante da crise requer mais democracia, mais direitos, mais informações, mais colaboração e mais empoderamento das pessoas. Vírus e pandemias não anulam a luta de classes, apenas a expressam de outra maneira, ainda mais severamente do que nos tempos normais.

E como se percebe, esta última perspetiva situa-se nos antípodas daquelas que pretendem cercear a democracia (e os direitos humanos básicos), aproveitando-se de modo autocraticamente ameaçador (e sem limites definidos) das prerrogativas que os próprios regimes democráticos preveem, mas apenas em situações de excepcional urgência.

Também por tudo isto, a escola pública está a ser desafiada, tendo deixado de fazer sentido insistir na manutenção de um modelo que já não consegue dar conta de grande parte das interrogações e dilemas educacionais e de cidadania(s) que lhe são colocados pela sociedade contemporânea. E porque mais à frente falarei de questões relacionadas com a gestão, antecipo já a crítica de Licínio Lima (2005) quando, convocando implicitamente a racionalidade taylorista, põe em causa a possibilidade de uma cidadania que seja resultante de uma autonomia escolar inexistente ou fortemente cerceada pela exacerbação centralizadora e controladora do Estado - "a fabricação de cidadãos produr̨idos em larga escala, através de processos estandardizados e sob controlo centralizado, não democrático e heterónomo, representa uma contradição fatal.” (p. 24).

Neste sentido, e sobretudo quando pensamos nas políticas públicas do Estado, não podemos deixar de pensar a Educação como possibilidade emancipatória e como direito humano básico; do mesmo modo que a escola pública democrática (ainda que precise ser reinventada para enfrentar melhor os desafios contemporâneos) não pode deixar de ser defendida como conquista histórica e civilizacional - uma "bandeira civilizacional", no dizer de Bruno Picoli (2020, p. 2). E não apenas no ensino básico obrigatório, mas também na educação superior, porque

[...] a defesa da escola pública, laica, gratuita, comprometida com o conhecimento científico, a liberdade de cátedra, o fortalecimento das políticas de cotas, o compromisso com um real universalismo em que caibam todos os rostos, as práticas antirracistas e contra as discriminações estarão na ordem do dia, sob risco de pesadas derrotas civilizatórias. (LEHER, 2019, p. 15). 
Mas hoje nada disso parece ser uma conquista definitiva, sendo muitos os entraves e retrocessos possíveis, sobretudo quando se trata de países e regimes em que vigora uma democracia meramente formal, fragil ou até autoritária, e com uma escola pública pouco consolidada ou, ao contrário, em países mais avançados democraticamente, onde, mesmo assim, esta instituição dá sinais de erosão face à sobrecarga crescente de novas missões e responsabilidades, desafiada pelas profundas mudanças do mundo contemporâneo. Isso tem induzido leituras diversas de sociólogos da educação que, por exemplo, interrogam-se sobre "para que servem as escolas?” (YOUNG, 2007), argumentando no sentido de que essas instituições se devem manter, mas assumindo uma indiscutível prioridade na criação de condições para que todos(as) possam apropriar-se do "conhecimento poderoso", nunca esquecendo ou deixando para trás, portanto, os(as) estudantes que já são desfavorecidos(as) pelas suas condições sociais e familiares (YOUNG, 2016). Outras perspetivas parecem ser menos propositivas, mas igualmente críticas: "Se ainda não estamos na liquidação brutal da forma escolar, estamos presenciando uma mutação da instituição escolar que pode ser associada a três tendências: desinstitucionalização, desvalorização e desintegração." (LAVAL, 2004, p. 26). Coincidindo em parte com o autor anterior, Mariano Fernández Enguita (2013, p. 158) procura explicar a "desinstitucionalização" da escola, considerando já estarmos a assistir "ao retorno ou devolução parcial” de funções educativas (de ensino e de aprendizagem) que em outras épocas foram assumidas por outras estruturas sociais, de tal modo que "o que a modernidade concentrou na escola floresce agora fora dela, ou lhe escapa.” (p. 158). Não se trata, evidentemente, de propor um (impossível e não desejável) retrocesso histórico, mas sim, como eu o interpreto, de relembrar que a Escola, enquanto instituição, já não detém o monopólio do ensino e já não é o único lugar da aprendizagem (legítima e legitimada) do conhecimento. Pode-se, por isso, dizer que "chegou o momento da escola-rede" que se deve constituir como "o nó central, o centro mobilizador [...] de projetos ambiciosos articulados em redes mais amplas, mais horizontais e menos hierárquicas, de geometria variável [...]." (FERNÁNDEZ ENGUITA, 2008, p. 23-24).

Porém, como ressalva este mesmo autor em texto mais recente, "por mais que a educação e a aprendizagem se dispersem", a escola continua a concentrar importantes recursos próprios e, sobretudo, a especificidade do seu conhecimento pedagógico. Isso faz da escola "não um simples nó numa possível articulação reticular", mas sim o lugar privilegiado para recursos que necessitam de coordenação e de "um propósito comum" (FERNÁNDEZ ENGUITA, 2013, p. 163). Esta última citação parece, pelo menos em parte, compatível com a ideia de um "bem comum local", que implica "parcerias sócio-educativas" envolvidas 
em um "processo de contratualização que co-responsabilize diversos organismos e entidades (entre elas a escola) na concretização de interesses comuns, no quadro de uma política educativa local" (BARROSO, 1998, p. 51-54). E em texto mais recente, em continuidade com esta linha argumentativa, Barroso (2013, p. 13) propõe "uma reflexão sobre a importância que a territorialização pode ter para a criação de uma 'nova ordem educativa local' e perspetiva o local como lugar de "construção de um bem comum educativo" (p. 15).

Como lembra Christian Laval (2004, p. 26), "Essas tendências são inseparáveis daquelas que visam a recomposição de um novo modelo de escola." Por isso parecem ser também convergentes, em grande medida, com a necessidade de a escola se libertar de funções que podem ser assumidas por organizações de natureza diversa, concentrando-se nas funções essenciais (ainda insuficientemente discutidas). É esta a visão de António Nóvoa ao sugerir cenários alternativos que tenham em conta os argumentos a favor de uma escola que inverta "a tendência para o transbordamento" de mandatos, e que se insira numa rede de relações e interações com outras instituições sociais, com o objetivo de criar e reforçar (na base de uma democracia deliberativa) o "espaço público da educação" (NÓVOA, 2014, p. 177; NÓVOA, 2002, passim).

Embora, na minha interpretação, Nóvoa proponha que diferentes instituições assumam, consoante as suas especificidades e de forma integrada, uma parte dos mandatos até agora assumidos pela escola pública (não pretendendo, portanto, que uma nova rede de relações e interações seja exclusivamente construída ou mediada pelas TIC), as redes sociais serão certamente pilares importantes a ter em conta - o que é convergente com o fato de muitas escolas/agrupamentos já estarem "a tirar partido do complexo sistema interorganizacional em que se integram” (LIMA, 2007, p. 152). Mais genericamente, como acrescenta Jorge Ávila de Lima no que diz respeito às "redes de governação" (sobre as quais eu não sou tão otimista relativamente às suas virtualidades), "é claro que a governação da educação implica um conjunto múltiplo de organizações e de conexões sem as quais a concretização dos objectivos públicos pode ficar comprometida" (LIMA, 2007, p. 165-166) ${ }^{4}$.

4

Um dos assuntos recentes da agenda das políticas educativas em Portugal diz respeito às novas atribuições legais que a Assembleia da República (poder legislativo) e o governo (poder executivo) aprovaram para serem assumidas pelos municípios e pelos conselhos municipais de educação (ver, por exemplo, lei $\mathrm{n}^{\circ}$ $50 / 2018$, de 16 de agosto e decreto-lei no 21/2019, de 30 de janeiro). Nesse sentido, as autarquias locais, enquanto organizações da administração pública local autônoma, viram reforçada a possibilidade da sua intervenção nas escolas públicas, nomeadamente em áreas de administração e gestão. Independentemente das análises críticas sobre as funções manifestas e latentes deste processo, e que é indispensável conhecer e acompanhar (ver, por exemplo, LIMA, 2015), não se poderá, no âmbito da territorialização das políticas e práticas educativas, deixar de considerar as autarquias locais como participantes incontornáveis na constituição de redes na educação e/ou na definição de um novo espaço público de educação. 
Uma reflexão mais aprofundada e sistemática sobre essas questões implicará, desde logo, começar por reconhecer que existem ambivalências e sobreposições conceituais, quer em relação ao que é entendido como rede (em sentido lato) ou redes de governação (em sentido restrito) (LIMA, 2007), quer, ainda, ao que é uma rede social ou o que deve ser entendido por rede na educação (a este propósito, por exemplo, SOUSA; DOROFTEI; ARAÚJO, 2013).

E essa mesma reflexão também poderá e deverá induzir a necessidade de aprofundar uma visão política, cultural e educativa crítica, não apenas por parte dos governantes, mas também dos gestores, professores e educadores (e da sociedade em geral) que impeça que as instituições escolares sucumbam às tendências mais nefastas da crescente digitalização de todas as práticas educativas e administrativas. A este propósito, por exemplo, a introdução e uso crescente, no âmbito do Estado e da administração pública, de plataformas informáticas, se por um lado trouxe algumas vantagens, também, por outro, aumentou consideravelmente o controle centralizado, reatualizando e multiplicando (paradoxalmente) os processos burocráticos.

Com efeito, ao contrário do que sugerem as melhores intenções, as redes eletrônicas, baseadas nas tecnologias da informação e da comunicação, não têm apenas virtualidades pelo fato de poderem permitir ou induzir processos menos hierárquicos e propiciadores de colaboração e de participação, nomeadamente na concretização de formas de governação (governance) mais democráticas. Em muitos casos, pelo contrário, como sublinha Licínio Lima (2012, p. 142), "aumentou a capacidade de controle hierárquico e centralizado mesmo no interior de 'redes' que não são necessariamente policêntricas nem menos hierarquizadas.” E no que diz respeito, mais especificamente, à administração e gestão das escolas públicas, acrescenta:

\footnotetext{
A hiperburocracia nas organizações educativas merece ser indagada, teórica e empiricamente, perante fenómenos de alta racionalização e informatização, extensão e grande escala, controle, estandardização, compartimentação do trabalho, mensuração, gestão e tratamento de dados, precisão, normativização, conhecimento pericial e regras técnicas detalhadas. (p. 154).
}

Assim sendo, tudo isso implicará igualmente perceber os limites e potencialidades das redes enquanto constitutivas (ou não) do espaço público (ou da esfera pública) - argumentos que não poderão deixar de ser convocados para discutir a proposta atrás referida de criação de um espaço público da educação. A esse propósito, aliás, em texto que agora revisitei, procurei chamar a atenção 
para a necessidade de aprofundar o debate "sobre a construção de um novo espaço público para se avançar substantivamente na problematização sobre a(s) autonomia(s) da escola pública.” E acrescentava:

A configuração de um novo espaço público, que expresse a reinvenção democrática do Estado e um novo protagonismo da Comunidade, é certamente difícil de imaginar a curto prazo. [...] Torna-se, talvez por isso, mais pertinente [...] quando [se] reclama ser necessário "mais teoria, mais vozes e mais política" nos estudos organizacionais. Desta forma, penso eu, poderá pelo menos contribuir-se para o fortalecimento democrático da esfera pública (agora em sentido habermasiano), que é, sem dúvida, uma etapa necessária [...] para pensar as possibilidades de construção de um novo espaço público. (AFONSO, 1999, p. 121, 133).

Seja como for, o fato é que a centralidade das redes (nomeadamente as redes sociais digitais) é cada vez mais uma realidade incontornável e uma problemática presente em um número crescente de ensaios e trabalhos de pesquisa, convergindo ou divergindo dos estimulantes contributos seminais de Manuel Castells. E já que falei de um autor de língua castelhana, aproveito para lembrar também o argentino Juan Carlos Tedesco que deixou uma obra e uma intervenção muito expressivas para o campo educacional, sobretudo latino-americano. Há quase duas décadas, em um dos textos publicados no Brasil, escrevia sobre a importância das redes e da sua relação com a autonomia das escolas:

[...] assim como o modelo institucional tradicional não pode ser mantido nas atuais circunstâncias históricas, também é preciso advertir que um desenho institucional baseado somente na autonomia das escolas pode aumentar os riscos de segmentação. A autonomia deve ser um estímulo para a vinculação e não para o isolamento. A ideia de rede constitui uma forma fértil para estimular conexões entre as instituições escolares que superem o formalismo tradicional e permitam intercâmbios reais, tanto em nível local como nacional e internacional. (TEDESCO, 2002, p. 27).

Do seu curriculum vitae sobressaem diversos cargos e responsabilidades, alguns dos quais na UNESCO - organização que, mais uma vez, está a tomar a iniciativa de lançar um grande debate sobre a educação em âmbito mundial. Mais concretamente, considerando que "o conhecimento e a aprendizagem são os maiores recursos renováveis disponíveis para a humanidade responder aos problemas e desafios com os quais se confronta atualmente", a UNESCO criou recentemente uma Comissão Internacional (da qual também faz parte António 
Nóvoa) que visa incentivar um amplo debate mundial sobre as alternativas possíveis e desejáveis para concretizar os Futuros da Educação, tendo como horizonte o ano de 2050 (UNESCO, 2019) 5 .

Em síntese, para concluir esta primeira parte, quero reforçar a ideia de que a defesa, o reforço e a reinvenção da escola pública (ou de um novo espaço público de educação) são tão mais urgentes quanto sabemos que os retrocessos são ainda maiores, quando se verifica, em diferentes países, uma crescente onda reacionária de populismos de direita ou de partidos e movimentos de extrema direita, alguns com forte expressão em governos eleitos em processos (apenas) formalmente democráticos. No que diz respeito ao Brasil, por exemplo, a militarização das escolas públicas tem subjacente o que Miguel Arroyo (2019, p. 3) já denunciou como sendo uma "criminalização das infâncias e adolescências populares". Para além desta militarização das escolas públicas, segundo Dirce Zan e Nora Krawczyk (2019), o programa Escola sem Partido, a inserção curricular do empreendedorismo e a possibilidade do ensino doméstico (homeschooling) são algumas das formas mais perversas de colocar em causa o trabalho das escolas públicas e dos professores, abrindo as portas para a desvalorização da educação emancipatória das novas gerações. Ainda em relação a esse tipo de ensino, outros autores salientam que:

[...] a defesa da educação domiciliar no Brasil está enraizada em valores religiosos fundamentalistas, apoiada e fortalecida por partidos, instituições e líderes religiosos alinhados ao movimento neoconservador que se propaga na atualidade em escala internacional; e [...] uma possível regulamentação do ensino domiciliar colocará em xeque o direito público subjetivo à Educação Básica, direito este assegurado após décadas de luta coletiva por uma escola gratuita, obrigatória, igualitária, inclusiva e laica. (CECCHETTI; TEDESCO, 2020, p. 13) ${ }^{6}$.

\footnotetext{
5 Veremos quem participa, como participa, e que consequências poderão advir de mais um relatório desta organização internacional, que precisaria voltar a ter um protagonismo mais efetivo e uma capacidade de influência mais progressista, dado o facto de estar (ou parecer estar) a ser muito secundarizada face a organizações como o Banco Mundial e a OCDE.

6 Referindo-se aos EUA, há já alguns anos, Michael Apple (2013, p. 36) escrevia: "Dois a três milhões de crianças foram retiradas de escolas públicas e privadas ou religiosas, na maioria das vezes, por razões ideológicas e religiosas conservadoras, e estão sendo educadas em casa. Enquanto o movimento da educação em casa é variado, estas decisões costumam ser movidas por ataques conservadores às escolas públicas e, mais uma vez, pelo medo do 'Outro'.”
} 
Por isso, concordo com Zan e Krawczyk (2019, p. 618) ao afirmarem que:

[...] a destruição dos espaços públicos e a apropriação da educação escolar por interesses particulares - ideológicos e econômicos - são dimensões do processo regressivo das conquistas sociais adquiridas ao longo de décadas e que estamos vendo serem destruídas num abrir e fechar de olhos, produzindo nem mais nem menos que a precarização e a desagregação da sociedade brasileira.

Nesta mesma linha, muitos autores denunciam a existência de "indícios de volta da barbárie” (CHARLOT, 2019, p. 163), e outros atribuem esta situação à emergência de uma nova direita militarista e antidemocrática (embora distinta da que apoiou o golpe militar de 1964) que percebeu que a educação é um dos terrenos propícios à sua atuação (ZIBECHI, 2020). E uma questão que não deixa de estar relacionada com a escola pública é a questão do Estado porque, "quando se destrói a ideia da escola pública, rui juntamente a ideia do Estado público, de direitos, de cidadanias. É uma radicalidade terrível." (ARROYO, 2019).

Por isso, a questão do Estado nesta conjuntura histórica exige, mais do que nunca, uma análise aprofundada. Se no contexto da atual crise pandêmica, em termos europeus, e não só, o Estado tem vindo a assumir um novo protagonismo em âmbito nacional (quase lembrando o Estado-providência nos países que têm sido mais cautelosos na preservação, ainda que temporariamente cerceada, de alguns direitos democráticos), também no patamar europeu sabemos que os movimentos nacionalistas de extrema-direita já vinham antes, e continuaram durante a crise, a pressionar para a volta de um Estado mais autoritário e com desmantelamento de direitos - o que, neste último caso, tem expressões várias em alguns países (Turquia, Hungria, Rússia, India...) onde os governos estão aproveitando-se da atual crise sanitária para reforçar decisões antidemocráticas e autocráticas que já tinham começado com reações de perseguição e ostracização aos refugiados, imigrantes, grupos étnicos, etc.

Por outro lado, quando olhamos para outros continentes (e, neste caso, por muitas razões, para países como o Brasil), sabemos que reivindicar a volta do Estado é também uma questão muito complexa. Entre outras razões, porque uma parte importante dos cidadãos perdeu a confiança no Estado, incapaz de acabar com a corrupção e a violência, desinteressado na definição de estratégias justas de combate às desigualdades (na saúde, na educação, no trabalho...), permitindo o exercício de poderes arbitrários que cavam brechas sociais profundas e fomentam confrontos, ódios e estigmas identitários, abandonando à própria sorte periferias habitadas por milhares de desempregados pobres, trabalhadores precários ou que sobrevivem de formas diversas na economia informal, como os que habitam 
as favelas das grandes metrópoles urbanas, cada vez mais à mercê de grupos criminosos organizados. Tudo isso ocorre num contexto social complexo em que um número crescente de pessoas é seduzido por discursos religiosos apocalípticos e promessas redentoras, agora agravados pela pandemia.

Aqui pode constatar-se claramente que muitas teorias (eurocêntricas) do Estado, não têm, de fato, capacidade hermenêutica para dar conta da realidade social e política de muitos países, nomeadamente latino-americanos. E aqui se percebe também a absoluta necessidade de movimentos sociais novos que lutem por reivindicações democráticas e agendas utopísticas, sem reincidir no erro de deixar de fora a democratização do próprio Estado, qualquer que seja a sua configuração.

\section{ESTADO E ADMINISTRAÇÃO PÚBLICA}

Há mais de duas décadas e meia, em um artigo publicado na revista "Administration \& Society", Mark Rutgers (1994, p. 395) pergunta: "Pode o estudo da administração pública prescindir do conceito de Estado?" Alguns anos depois, Michael Spicer (2001, p. 1), escreve: "A questão do que constitui uma boa administração pública tem sido frequentemente vista como uma questão que pode ser examinada separadamente de qualquer visão particular do Estado." Por seu lado, Jean-Claude Thoenig (2006, p. 249) sublinha que "os estudos das organizações públicas ganham muito em manter um contacto próximo com as análises das políticas", e Christopher Pollitt (2010), ao chamar a atenção para o fato de a administração pública ter permanecido um campo multidisciplinar, apesar das tentativas de ser definido como uma disciplina, escreve: "O que unifica a administração pública é o seu objeto - o Estado, o setor público e domínio público - não são os objetivos, teorias ou métodos." (p. 292). Estas citações parecem, de algum modo, remeter à questão weberiana da distinção entre política e administração. Aliás, apesar das mudanças que sempre ocorrem na longa duração, subsistem práticas (agora, paradoxalmente, reatualizadas por processos informáticos) que mostram que a administração pública não se desfiliou totalmente da velha racionalidade burocrática, ainda que o exercício da suposta neutralidade e autonomia técnica e instrumental pareça estar bastante secundarizado face às exigências dos cidadãos que dão prioridade a uma maior eficiência e eficácia dos serviços.

Compreende-se, assim, que a "visão de Administração Pública - assente numa dicotomia fictícia e numa 'neutralidade' desde cedo qualificada como mito e justamente cauterizada como ocultando a verdadeira natureza do Estado - foi, porém, sendo crescentemente posta em causa [...]." (MAGALHÃES, 1994, p. 
14-15). Aliás, a literatura também indica que a ineficácia de uma administração pública guiada apenas por regras formais ou por normativos legais terá sido uma das razões que levaram os primeiros defensores da separação da administração pública da política a advogar a favor da constituição da administração como campo científico próprio.

De qualquer modo, numa visão diacrônica, foram dominantes em diferentes momentos históricos ou conviveram (e ainda convivem) em tensão e contradição, quer a argumentação favorável à neutralidade da administração pública face ao Estado, quer a procura de cientificização da administração pública, quer, ainda, a defesa de uma administração pública a serviço dos cidadãos e aberta à sua participação e escrutínio democráticos, eventualmente reconfigurada como novo serviço público (sobre esta última possibilidade, ver, por exemplo, Denhardt; Denhardt, 2015). Se, pelo menos, nos últimos dois séculos, a administração pública tem sido permeável a inovações técnicas, a mudanças nos valores e princípios éticos, a influências político-ideológicas, a avanços e recuos teórico-concetuais, o certo é que a "administração pública é pública, e, portanto, dissociá-la da política é praticamente impossível e democraticamente indesejável.” (MOTTA, 2013, p. 87). Licínio Lima (2010, on-line), depois de se referir a períodos anteriores, também sublinha que, atualmente, "registra-se uma tendência no sentido de recusar a separação entre política e administração: toda a administração é um ato político e, no limite, não existe política sem administração."

Não esquecendo a nossa natureza política como homens e mulheres, ou seja, a incontornável politicidade de que falava Paulo Freire, e sabendo que a Política está muito longe de se realizar ou esgotar apenas na ação dos partidos políticos, não podemos, por isso mesmo, deixar de reconhecer que a forma como se (re)configura e materializa a administração pública não é indiferente à natureza do Estado, bem como, mediadas por este, às demandas das diferentes instâncias e níveis de regulação subnacionais, internacionais e supranacionais, tal como não é imune às pressões e influências democráticas dos cidadãos.

\section{ADMINISTRAÇÃO PÚBLICA E ADMINISTRAÇÃO EM EDUCAÇÃO}

Sendo certo que a administração das escolas públicas é parte constitutiva da administração pública, em sentido lato, julgo que este fato, salvo as devidas exceções, não tem tido particular relevância (ou não tem sido problematizado criticamente) nos trabalhos que se referenciam ao campo de pesquisa da política e administração da educação. Esta é mais uma hipótese de trabalho do que uma conclusão consistente, dada a limitada revisão da literatura que fiz sobre este 
assunto. A este propósito, aliás, um dos artigos que chamou a minha atenção interrogava sobre as razões pelas quais a administração pública no EUA teria, em determinado momento, ignorado a educação (RAFFEL, 2007).

Embora considere importante perceber, de forma mais sistemática, as relações entre administração pública e administração da educação, tendo em conta não apenas a literatura portuguesa e brasileira, mas também a literatura especializada disponível e referente a outros contextos nacionais, cinjo-me aqui, mais modestamente, a algumas notas relativas ao sistema educativo português e, mais especificamente, às escolas públicas (integradas ou não integradas em agrupamentos).

No caso português, os caminhos iniciais da constituição do campo da administração educacional (em sentido amplo) ou da administração escolar (em sentido restrito) foram, em graus diversos, influenciados pelos contributos do direito administrativo e da (ciência) da administração pública. A esse propósito, Licínio Lima escreveu (1996, p. 26):

A administração escolar terá sido mais administração do que escolar, no sentido em que se centrou mais na administração do sistema do que no estudo da escola (e mais nas teorias gerais da administração), tal como a organizaçãa escolar se revelou mais sinónimo de macro-organização, isto é, de organização do sistema escolar, do que de escola como organização.

Em Portugal, a administração educacional, como disciplina e área de pesquisa acadêmica, acompanhou a expansão e consolidação das ciências da educação, as quais, por sua vez, foram impulsionadas pela formação de professores nas instituições de ensino superior, mas continuou a consolidarse posteriormente nos cursos de pós-graduação (mestrados e doutoramentos). Mais precisamente, no final dos anos 1980, início dos anos 1990, quando uma nova geração de professores(as) e pesquisadores(as) começa a realizar, defender e divulgar, no seio da comunidade de referência, os seus trabalhos de investigação, é que se desenvolve gradualmente a disciplina de Organização e Administração Escolar/Administração Educacional. É nesse contexto que são defendidas teses de doutoramento influenciadas inicialmente pela ciência política e pelas teorias da administração pública (por exemplo, FORMOSINHO, 1987; FERNANDES, 1992). Para além do modelo weberiano racional/burocrático, outras teses de doutoramento convocam pela primeira vez diferentes modelos referenciáveis à sociologia das organizações, como os modelos político, anárquico, de sistema social, neoinstitucional... Exemplifica bem este caso, por ser precursora de uma abordagem teórico-conceptual mais ampla, a tese "A escola como organização e a participação na organização escolar" (LIMA, 1991), que veio influenciar 
fortemente os trabalhos do grupo de pesquisa em administração educacional da Universidade do Minho, a que seguiram outros grupos no país, nomeadamente na Universidade de Lisboa, com a coordenação de João Barroso, ou na Universidade de Aveiro, com a coordenação de Jorge Adelino Costa - autores que, tal com Licínio Lima, têm muitos dos seus trabalhos publicados no Brasil e são também responsáveis pela inserção e expansão institucional (na docência e na pesquisa) da área da administração educacional'.

Para além das abordagens específicas em cada país, o que tem sido relativamente convergente em trabalhos de colegas portugueses e brasileiros, nomeadamente no âmbito de eventos científicos promovidos pela Associação Brasileira de Política e Administração da Educação (ANPAE) e/ou pelo Fórum Português de Administração Educacional ou, ainda, através de artigos incluídos nas respetivas revistas e em outras publicações acadêmicas, são seguramente as conexões da administração educacional e/ou da gestão escolar com as agendas político-ideológicas dominantes em determinadas conjunturas sócio-históricas (agendas que se inscrevem igualmente no campo mais amplo da sociologia das políticas educacionais). Por isso, não há dúvida de que fica mais robusta a compreensão do que acontece nas escolas públicas quando, por exemplo, se consideram os modelos de análise da sociologia das organizações (educativas), a natureza e transformações do Estado, as orientações/adesões político-ideológicas dos governos nacionais e as orientações e condicionantes com origem em instâncias internacionais e transnacionais.

De igual modo, a própria administração pública, como campo de ação profissional ou como campo de investigação, está muito longe de se circunscrever a visões meramente racionais-legais ou a orientações normativas. Existem perspetivas críticas, nomeadamente no Brasil, que refletem sobre alguns dos possíveis sentidos de mudança e apontam concepções alternativas (DAVEL; ALCADIPANI, 2003; FARIA, 2009; VALADARES, et al., 2017). Curiosamente, na literatura brasileira tenho encontrado diversas críticas às teorias euronorteamericanas na área da administração e gestão das empresas, mais até do que na área dos estudos de administração e gestão centrados na escola - refiro-me sobretudo aos ensinos fundamental e médio, em que os estudos ainda incidem muito sobre a gestão democrática e a figura do diretor, mas também à educação superior, ainda que, neste caso, o estudo das universidades como organizações educativas esteja, comparativamente, mais avançado. Autores mais radicais chegam mesmo a escrever que no Brasil as "teorias administrativas têm como 
base uma espécie de 'racismo epistêmico', desconsiderando o conhecimento que não é produzido nas localidades tidas 'centrais [...]'." (CARRIERI; CORREIA, 2020, p. 60).

Pensando de forma mais específica na realidade portuguesa, a administração das escolas públicas e a análise crítica e diacrônica dos respectivos modelos de direção e gestão têm constituído temáticas preferenciais dos estudos da disciplina de administração educacional. Em interface ou não com esta última, o quotidiano da escola como organização complexa - aí incluídas as práticas e poderes dos atores ou a acção organizacional, os processos de negociação, as tensões, as contradições, as funções, os rituais e outras dimensões simbólicas -, tem sido elucidado, com sustentação em investigação empírica e em diferentes modelos de análise, sobretudo pela sociologia das organizações educativas. É no âmbito desta última disciplina que, de forma não insularizada e tecendo pontes e sinergias, os estudos sobre a escola têm vindo a ganhar uma nova centralidade interpretativa. Como elucida uma vez mais Licínio Lima (2008, p. 7):

Apoiado pela emergência de uma sociologia das organizações educativas e procurando estabelecer pontes com a análise das políticas educacionais, com modelos, imagens e metáforas para a interpretação das organizações sociais formais, e com a crítica às ideologias organizacionais e administrativas, tradicionalmente de extracção empresarial, o estudo da escola vem ganhando centralidade. Trata-se de um processo complexo, mas também muito estimulante, de construção de um objeto de estudo que, no passado, foi frequentemente apagado [...] entre olhares macroanalíticos que desprezaram as dimensões organizacionais dos fenómenos educativos e pedagógicos, e olhares microanalíticos, exclusivamente centrados no estudo da sala de aula e das práticas pedagógico-didácticas. [...] a mesoabordagem da escola parece constituir uma forma de integração/articulação de objectos de estudo macroestruturais (o Estado, os sistemas político e económico, a macro-organização do sistema escolar, etc.) e os objectos de estudo de tipo microestrutural (a sala de aula, os grupos/subgrupos de formação, os actores e as suas práticas em contextos específicos de acção).

Em síntese, os estudos organizacionais, em geral, e o estudo das organizações educativas, em particular, têm acolhido e desenvolvido perspetivas teóricas e conceituais muito distintas. As perspetivas que se caracterizam por uma maior radicalidade (ética e política) partilham pressupostos dos estudos organizacionais críticos ou convocam autores cujas contribuições (também) são referenciáveis a esses estudos, como é o caso de Paulo Freire (sobre este propósito, ver LIMA, 2013). No entanto, no caso português, ainda que os autores dos estudos organizacionais críticos sejam conhecidos e convocados, não se pode dizer que essa presença na administração educacional ou na sociologia das organizações educativas seja de tal modo expressiva que constitua já uma 
linha de pesquisa facilmente reconhecida ou com contribuições imediatamente associáveis a determinados autores ou grupos de investigação. Pelo contrário, no caso brasileiro, os estudos organizacionais críticos (quer em educação, quer, sobretudo, fora desta área) são, na sua gênese, tributários de alguns reconhecidos autores, entre os quais se conta Maurício Tragtenberg. No entanto, este autor, que "traçou uma linha própria de pensamento" (desde logo, em "Burocracia e Ideologia"), ainda que tenha uma grande proximidade com a teoria crítica, fixouse "nos referenciais weberianos, marxistas e anarquistas" e não é considerado um intelectual frankfurtiano (FARIA, 2009, p. 510). De qualquer modo, nesta ou noutra direção, contributos diversos no Brasil têm continuado a consolidar uma linha de trabalho e pesquisa facilmente identificável sobre estudos organizacionais críticos, a qual valerá a pena, noutra ocasião, revisitar mais demoradamente.

\section{NOTAS FINAIS}

Não quero fechar este texto sem fazer um breve apontamento sobre o apelo contido no subtítulo do XXIX Simpósio da ANPAE, realizado em abril de 2019: "Resistência ativa para uma agenda democrática com justiça social". No rescaldo da campanha e na sequência das últimas eleições presidenciais brasileiras, o que começara a acontecer deixava antever um período de forte refluxo dos direitos, liberdades e garantias, três décadas depois da aprovação da Constituição democrática. Tornava-se evidente o que já em alguns países estava em curso, e noutros viria a tornar-se uma realidade: que muitas democracias estão hoje a morrer por meios diferentes, já não tanto de formas violentas ou golpes de Estado, mas, cada vez mais, pela mão dos próprios dirigentes políticos (democraticamente) eleitos (LEVITSKY; ZIBLATT, 2018; MELEGH, 2019). Neste contexto, “o circuito político apresenta-se como um condomínio exclusivo da plutocracia destituído de qualquer verniz democrático. A soberania popular fica ainda mais comprimida, deixando a sociedade a um fio da autocracia explícita." (SAMPAIO, 2020, p. $274-275)$.

Às vésperas de mais um aniversário da Revolução dos Cravos, ocorrida em 25 de abril de 1974, quando o primeiro esboço deste texto foi lido na sessão de abertura do evento anteriormente referido, relembrei a canção que Chico Buarque compôs (e posteriormente refez em alguma das suas passagens) em homenagem a essa mudança profunda do regime autoritário português para a democracia. A versão original de "Tanto mar" era entusiástica e a versão posterior já era triste, mas ainda com esperança: "Foi bonita a festa, pá [cara]/ Fiquei contente/ Ainda 
guardo renitente/ Um velho cravo para mim/ Já murcharam tua festa, pá [cara]/ Mas certamente/ Esqueceram uma semente/ Em algum canto de jardim..." (CHICO BUARQUE, 1978).

Um ano depois do simpósio, o alastramento, por vários meios, dos ataques (e consequentes retrocessos) a todas as dimensões das políticas de justiça (da redistribuição ao reconhecimento e à representação) ${ }^{8}$ tem vindo a ser potenciado pela forma como tem sido gerida a crise sanitária resultante da pandemia do Covid-19. Mas "a politização da pandemia está longe de ser um fenômeno brasileiro. É tão global quanto a presença do próprio vírus." (NEIBURG, 2020, p. 3). Com efeito, vários dirigentes políticos têm agido de forma autoritária ou mesmo neofascista, aproveitando a atual crise. É o caso de Orbán, na Hungria; Erdoğan, na Turquia; Duterte, nas Filipinas; Bukele, em El Salvador; ou Ortega, na Nicarágua. E neste contexto, é ainda mais difícil resistir politicamente, socialmente e culturalmente quando esta pandemia nos enfraquece e nos diz "Para não esquecermos como somos frágeis" (STING, 1987)?.

Em qualquer situação, as experiências de resistência podem contarse ou podemos tentar compreendê-las, mas nunca poderão ser transferidas (mimeticamente) como modelos para contextos e tempos históricos, políticos e culturais distintos. Tenho, porém, uma convicção profunda: este grande país tem inscritas na sua História muitas e longas experiências de resistência que não podem ser apagadas da memória. A Educação é um dos mais importantes espaços de resistência, sobretudo quando nele se inscrevem as lutas de organizações coletivas com legitimidade democrática.

O exemplo mais recente foi a realização, em maio de 2018, da Conferencia Nacional Popular de Educação (CONAPE), em defesa da escola pública (OLIVEIRA; SÜSSEKIND, 2019). E muitos outros exemplos surgirão para lutar pela educação e pela democracia. A partir da minha própria experiência de seis anos à frente da Sociedade Portuguesa de Ciências da Educação (SPCE), não posso deixar de lembrar que atravessámos anos de crise, de regressão de direitos e de austeridade imposta pela troika, e que uma das aprendizagens mais marcantes foi a de perceber que uma organização científica pode ser

8 Sinalizo, apenas a título de exemplo, a concepção de justiça assente nas dimensões da redistribuição, do reconhecimento e da representação/participação que Nancy Fraser tem vindo a atualizar e propor em diferentes e importantes trabalhos (por exemplo, Fraser, 2008).

9 "Lest we forget how fragile we are" (Sting, 1987, in Fragile, do álbum Nothing like the Sun). 
[...] um outro lugar para mobilizar novos conhecimentos e saberes que nos façam avançar profissionalmente e humanamente, ou, quando necessário, um lugar (também) para resistir às intempéries que possam provocar a erosão dos sentidos mais democráticos e emancipatórios da Educação. (AFONSO, 2016, p. vii).

Este é, creio eu, e mais uma vez na sua história, também um dos desafios importantes da ANPAE para os próximos anos.

\section{REFERÊNCIAS}

AFONSO, Almerindo J. A(s) autonomia(s) da escola na encruzilhada entre o velho e o novo espaço público. Inovação, v. 12, n. 3, p. 121-137, 1999.

AFONSO, Almerindo J.; LUCIO-VILLEGAS, Emílio. Estado-nação, educação e cidadanias em transição. Revista Portuguesa de Educação, v. 20, n. 1, p. 77-98, 2007.

AFONSO, Almerindo J. Notas de abertura do XIII Congresso da SPCE. In: GOMES, Cristina A. et al (Eds.). Atas do XIII Congresso da Sociedade Portuguesa de Ciências da Educação: fronteiras, diálogos e transições em educação. Viseu: Escola Superior de Educação de Viseu, 2016. p. vi-vii.

ANDERSON, Benedict. Me gustan los elementos utópicos del nacionalismo. [Entrevista concedida a Lorenz Khazaleh]. Debats, v. 130, n. 1, p. 87-91, 2016.

APPLE, W. Michael. As tarefas do estudioso/ativista crítico em uma época de crise educacional. Revista Pedagógica, v. 1, n. 30, p. 29-66, 2013.

ARROYO, Miguel. Escolas militarizadas populares. Entrevista concedida a Ana Luiza Basilio. Carta Capital, 12 set. 2019. p. 1-8.

BARROSO, João. Descentralização e autonomia: devolver o sentido cívico e comunitário à escola pública. Revista Colóquio/Educação e Sociedade, n. 4, p. 32-58, 1998.

BARROSO, João. Os liceus: organização pedagógica e a administração dos liceus (1836-1960). 1993. Tese (Doutoramento) - Universidade de Lisboa, Lisboa, 1993. 
BARROSO, João. A emergência do local e os novos modos de regulação das políticas educativas. Educação, Temas e Problemas, n. 12-13, p. 13-25, 2013.

BARROSO, João. Descentralização, territorialização e regulação sociocomunitária da educação. Revista de Administração e Emprego Público, n. 4, p. 7-29, 2018.

BIANCHI, Álvaro. O conceito de Estado em Max Weber. Lua Nova, n. 92, p. 79-104, 2014.

BOURDIEU, Pierre; PASSERON, Jean-Claude. La reproduction: éléments pour une théorie du système d'enseignement. Paris: Minuit, 1970.

BOURDIEU, Pierre. Sobre o Estado: cursos no Collège de France (1989-92). São Paulo: Companhia das Letras, 2014.

CARRIERI, Alexandre P.; CORREIA, Gabriel. Estudos organizacionais no Brasil: construindo acesso ou replicando exclusão? Revista de Administração de Empresas, v. 60, n. 1, p. 56-63, 2020.

CECCHETTI, Elcio; TEDESCO, Anderson. Educação Básica em "xeque”: homeschooling e fundamentalismo religioso em tempos de neoconservadorismo. Práxis Educativa, v. 15, e2014816, p. 1-17, 2020.

CHARLOT, Bernard. A questão antropológica na Educação quando o tempo da barbárie está de volta. Educar em Revista, v. 35, n. 73, p. 161-180, 2019.

COSTA, Jorge Adelino. Administração escolar: imagens organizacionais e projecto educativo de escola. 1995. Tese (Doutoramento) - Universidade de Aveiro, Aveiro, 1995.

DAVEL, Eduardo; ALCADIPANI, Rafael. Estudos críticos em administração: a produção científica brasileira nos anos 1990. Revista de Administração de Empresas, v. 43, n. 4, p. 72-85, 2003.

DENHARDT, Janet V.; DENHARDT, Robert B. The new public service revisited. Public Administration Review, v. 75, n. 5, p. 664-672, 2015. 
FARIA, José H. Teoria crítica em estudos organizacionais no Brasil: o estado da arte. Cadernos EBAPE.BR., v. 7, n. 3, p. 509-515, 2009.

FERGUSON, Kathy E. On bringing more theory, more voices and more politics to the study of organization. Organization, v. 1, n. 1, p. 81-99, 1994.

FERNANDES, A. Sousa. A centralização burocrática no ensino secundário: evolução do sistema educativo português durante os períodos liberal e republicano (1836-1926). 1992. Tese (Doutoramento) - Universidade do Minho, Braga, 1992.

FERNÁNDEZ ENGUITA, Mariano. Centros, redes, proyectos. In: FERNÁNDEZ ENGUITA, Mariano; TERRÉN, Eduardo (org.). Repensando la organización escolar: crisis de legitimidade y nuevos desarrollos. Madrid: Akal, 2008. p. 23-39.

FERNÁNDEZ ENGUITA, Mariano. El aprendizaje difuso y el declive de la instituición escolar. RASE: Revista de la Asociación de Sociología de la Educación, v. 6, n. 2, 150-167, 2013.

FORMOSINHO, João. Educating for Passivity. A study of portuguese education (1926-1968). 1987. Tese (Doutoramento) - Universidade de Londres, Londres, 1987.

FRASER, Nancy. Escalas de justicia. Barcelona: Herder, 2008.

GIL, José. A pandemia e o capitalismo numérico. Público, ano XXXI, n. 10.946, pp. 10-11, 13 abr. 2020.

GIROUX, Henry. Terrorismo pedagógico y esperanza en tiempos de políticas fascistas. E1 Viejo Topo, n. 382, p. 64-72, 2019.

LAVAL, Christian. La escuela no es una empresa. Barcelona: Paidós, 2004.

LEHER, Roberto. Apontamentos para análise da correlação de fporças na educação brasileira: em prol da frente democrática. Educação \& Sociedade, v. 40, e0219831, p.1-18, 2019.

LEVITSKY, Steven; ZIBLATT, Daniel. Como morrem as democracias. Amadora: Vogais, 2018. 
LIMA, Jorge Ávila. Redes na educação: questões políticas e conceptuais. Revista Portuguesa de Educação, v. 20, n. 2, p. 151-181, 2007.

\section{LIMA, Licínio C. A Escola como organização e a participação na organização} escolar: um estudo da escola secundária em Portugal (1974-1988). 1991 Tese (Doutoramento) - Universidade do Minho, Braga, 1991.

LIMA, Licínio C. Construindo um objecto: para uma análise crítica da investigação portuguesa sobre a escola. In: BARROSO, João (org.). O estudo da escola. Porto: Porto Editora, 1996. p. 14-39.

LIMA, Licínio C. Escolarizando para uma educação crítica: a reinvenção das escolas como organizações democráticas. In: TEODORO, António; TORRES, Carlos A. (org.). Educação crítica e utopia: perspectivas para o século XXI. Porto: Afrontamento, 2005. p. 19-31.

LIMA, Licínio C. A escola como organização educativa. São Paulo: Cortez, 2008.

LIMA, Licínio C. Administração escolar (verbete). In: OLIVEIRA, Dalila A. et al (org.). Dicionário: trabalho, profissão e condição docente. Belo Horizonte: UFMG/Faculdade de Educação, 2010. Disponível em: https://gestrado.net.br/ pdf/355.pdf. Acesso em: 5 abr. 2020.

LIMA, Licínio C. Elementos de hiperburocratização da administração educacional. In: LUCENA, Carlos; SILVA JÚNIOR, João dos Reis (org.). Trabalho e educação no século XXI: experiências internacionais São Paulo: Xamã, 2012. p. 129-158.

LIMA, Licínio C. Organização escolar e democracia radical: Paulo Freire e a governação democrática da escola pública. 5. ed. São Paulo: Cortez, 2013.

LIMA, Licínio C. O Programa "Aproximar Educação", os municípios e as escolas: descentralização democrática ou desconcentração administrativa? Questões Atuais de Direito Local, n. 5, p. 7-24, 2015.

LINS RIBEIRO, Gustavo. El precio de la palabra: la hegemonia del capitalismo electrónico-informático y el googleísmo. Desacatos-Revista de Ciencias Sociales, n. 56, p. 16-33, 2018. 
MAGALHÃES, José. Um olhar português sobre o Relatório Gore. In: AL GORE (Coord.). Reinventar a Administração pública. Lisboa: Quetzal, 1994. p. 9-24.

MELEGH, Attila. Momentos de hegemonia: raízes históricas do capitalismo autoritário e a política educacional - o caso da Hungria. Lutas Sociais, v. 23, n. 42, p. 9-22, 2019.

MOTTA, Paulo R. M. O estado da arte da gestão pública. Revista de Administração de Empresas, v. 53, n. 1, p. 82-90, 2013.

NEIBURG, Federico. La politización de la pandemia, los féretros vacíos y el abismo brasileño. Nueva Sociedad, maio, p. 1-9, 2020.

NÓVOA, António. O espaço público de educação: imagens, narrativas e dilemas. In: NÓVOA, António (org.). Espaços de Educação, Tempos de Formação. Lisboa: FCG, 2002. p. 237-263.

NÓVOA, António. Educação 2021: para uma história do futuro. Educação, Sociedade \& Culturas, n. 41, p. 171-185, 2014.

OLIVEIRA, Inês B.; SÜSSEKIND, Maria Luiza. Tsunami conservador e resistência: a CONAPE em defesa da educação pública. Educação \& Realidade, v. 44, n. 3, e84868, p.1-22, 2019.

PICOLI, Bruno A. Homeschooling e os irrenunciáveis perigos da educação: reflexões sobre as possibilidades de educação sem escola no mundo plural a partir de Arendt, Biesta e Savater. Práxis Educativa, v. 15, e2014535, p. 1-22, 2020.

POLLITT, Christopher. Envisioning public administration as a scholarly field in 2020. Public Administration Review, Special issue, p. 292-294, 2010.

RAFFEL, Jeffrey A. Why public administration ignored public education, and does it matter? Public Administration Review, v. 67, n. 1, p. 135-151, 2007.

RUTGERS, Mark. Can the study of public administration do without a concept of the State?". Administration \& Society, v. 26, n. 3, p. 395-412, 1994. 
SALAS, Miguel. El vírus no puede atropelar derechos y libertades. Sin Permiso, p. 1-5. Disponível em: https://www.sinpermiso.info/textos/el-virus-no-puedeatropellar-derechos-ylibertades. Acesso em: 5 abr. 2020.

SAMPAIO, Plínio A. Ascenso da "nova direita" na América Latina: o caso brasileiro. In: ÁLVAREZ, Jairo Estrada; MARTÍN, Carolina Jiménez; PUELLOSOCARRÁS, José Francisco (eds.). Contra Nuestra América: estrategias de la derecha en el siglo XXI. Buenos Aires: Clacso, 2020. p. 259-282.

SASSEN, Saskia. Incompletud y la posibilidad de hacer ¿Hacia una ciudadanía desnacionalizada? Revista Mexicana de Ciencias Políticas y Sociales, ano LXI, n. 226, p. 1017-140, 2016.

SOUSA, Sofia B.; DOROFTEI, Alexandra O.; ARAÚJO, Helena C. Networks in Education: an analysis of selected discourses. Interchange, n. 44, p. 311-331, 2013.

SPICER, Michael W. Public administration and the state: a postmodern perspective. Tuscaloosa: University of Alabama Press, 2001.

TEDESCO, Juan Carlos. Os fenômenos de segregação e exclusão social na sociedade do conhecimento. Cadernos de Pesquisa, n. 117, p. 13-28, 2002.

THOENIG, Jean-Claude. El rescate de la publicness en los estúdios de la organización. Gestión y Política Pública, v. 15, n. 2, p. 229-258, 2006.

TSAVKKO-GARCÍA, Raphael; DÍAZ, Koldo. País digital: transnacionalismo e comunidade imaginada basca. Estudos em Comunicação, v. 1, n. 28, p. 173187, 2019.

UNESCO. Futures of Education. Learning to become. Paris: Unesco 2019. https://en.unesco.org/futuresofeducation/. Acesso em: 5 abr. 2020.

VALADARES, Josiel et al. Administração pública sob a ótica dos estudos críticos: reflexões, interlocuções e tendências. Administração Pública e Gestão Social, v. 1, n. 1, p. 31-42, 2017.

WEBER, Max. Ciência e política: duas vocações. São Paulo: Martin Claret, 2015. 
YOUNG, Michael. Para que servem as escolas? Educação \& Sociedade, v. 28, n. 101, p. 1287-1302, 2007.

YOUNG, Michael. Por que o conhecimento é importante para as escolas do século XXI? Cadernos de Pesquisa, v. 46, n. 159, p. 18-37, 2016.

ZAN, Dice; KRAWCZYK, Nora. Ataque à escola publica e à democracia: notas sobre os projetos em curso no Brasil. Retratos da Escola, v. 13, n. 27, p. 607620, 2019.

ZIBECHI, Raúl. Una nueva derecha militante y com apoyo "popular". In: NORTH, Liisa; RUBIO, Blanca; ACOSTA, Alberto (ed.). Concentración económica y poder político en América Latina. Buenos Aires: Clacso, 2020. p. $445-461$.

\begin{abstract}
Almerindo Janela Afonso
Sociólogo, Doutorado em Educação (Sociologia da Educação), professor do Departamento de Ciências Sociais da Educação e pesquisador do Centro de Investigação em Educação da Universidade do Minho (Portugal), coordenador da especialidade de sociologia da educação e política educativa do doutoramento em Ciências da Educação, ex-Presidente da Sociedade Portuguesa de Ciências da Educação. E-mail: ajafonso@ie.uminho.pt
\end{abstract}

Recebido em 27/05/2020

Aprovado em 22/06/2020 